\title{
EVALUATION OF THE USE OF ZIRCONIA POROUS SCAFFOLD IN THE REPAIR OF OROANTRAL FISTULA
}

\author{
Karim E. Mokhtar ${ }^{1} B D s$, Ahmed S. Elmahallawy² $P h D$, Adham A. Elashwah ${ }^{3} P h D$
}

\begin{abstract}
INTRODUCTION: There is a variety of treatment modalities for oroantral defects based on repair of soft tissue component only of the defect. However, bone regeneration is needed to allow for later restoration of the missing tooth.

OBJECTIVE: The aim of this study was to evaluate the efficacy of zirconia porous scaffold in oroantral defects.

MATERIALS AND METHODS: This study was conducted on ten patients suffering from oroantral defects of more than three weeks duration and having a width of at least five millimeters $(\mathrm{mm})$. The patients were treated with placement of a custom made zirconia porous scaffold along with buccal advancement flap after a virtual surface for bone model was reconstructed from the cone-beam computed tomography and printed by stereolithography 3D printing method.

RESULTS: Clinically, there was a significant improvement in wound healing in $80 \%$ of the cases across the follow up period with only $20 \%$ of the patients the wound didn't heal due to infected wound margins and the full scaffold was lost prior to the end of the follow-up period and required further treatment later on. Pain intensity decreased throughout the follow-up period with the maximum pain intensity was only immediately postoperative. Radiographically, there was a significant increase in bone density from the baseline by 41.2 percentage change. CONCLUSION: Zirconia porous scaffold is a biocompatible material that enhances new bone formation in closure of oroantral fistulas through its high porosity and clear interconnected porous surface which are a suitable environment for osteoblastic activity.
\end{abstract}

Keywords: Oro-antral fistula, Zirconia scaffold, Bone model.

1. Oral \& Maxillofacial Surgery department, Faculty of Dentistry, Alexandria University

2. Professor of Oral \& Maxillofacial Surgery department, Faculty of Dentistry, Alexandria University

3. Assistant Professor of Oral \& Maxillofacial Surgery department, Faculty of Dentistry, Alexandria University

\section{INTRODUCTION}

The major cause of odontogenic maxillary sinusitis is iatrogenic, one of which is the oroantral communications, accounting for $47.5 \%$ of iatrogenic causes (1). This is the pathological loss of hard and soft tissues between the oral cavity and the maxillary sinus leading to a connection of both cavities. If this is not diagnosed or managed properly, there is a risk that the pathway in between becomes epithelialized resulting in an oroantral fistula (OAF). This epithelium comes from granulation tissue filling the tract or from polyposis of the sinus membrane. Epithelialization lasts for more than 48 hours and is completed after seven days (2-4).

When chronic oroantral fistula defects are wider than $5 \mathrm{~mm}$ and persist for more than 3 weeks, a secondary surgical intervention is required. Defects less than $3 \mathrm{~mm}$ in width and without epithelialization might heal spontaneously in the absence of infections (5). The most common flaps used to treat OAC include buccal advancement flaps, palatal rotation and palatal transposition flaps, tongue flaps, and nasolabial flaps. There is also an increased use of the buccal fat pad (BFP) (6). The disadvantages of these are the high morbidity, discomfort for the patient, and no possibility to repeat the same technique after surgical failure (7).

Scaffold design and fabrication are major areas of biomaterial research, and they are also important subjects for tissue engineering and regenerative medicine research (8). Scaffold plays a unique role in tissue regeneration and repair. During the past two decades, many works have been done to develop potentially applicable scaffold materials for tissue engineering. Scaffolds are defined as three-dimension porous solid biomaterials designed to perform some or all of the following functions: (a) promote cell-biomaterial interactions, cell adhesion, and extracellular matrix deposition, (b) permit sufficient transport of gases, nutrients, and regulatory factors to allow cell survival, proliferation, and differentiation, (c) biodegrade at a controllable rate that approximates the rate of tissue regeneration under the culture conditions of interest, and (d) provoke a minimal degree of inflammation or toxicity in vivo (9).

Hence, this study was carried out in order to evaluate the use of a custom made zirconia porous scaffold for internal augmentation for closure of oroantral fistula.

\section{MATERIALS AND METHODS}

The ethical clearance was obtained by the ethical committee before starting the study, the selected patients were informed about the nature of the study and informed consents were obtained.

This study was a Prospective one and was done on ten patients suffering from oroantral defects selected from outpatient Clinic of Oral and Maxillofacial Surgery Department, Faculty of Dentistry, Alexandria University.

Inclusion criteria for the study involved patients of both sexes, patients having oroantral defects of at least three weeks duration and diameter of at least $5 \mathrm{~mm}$, while the exclusion criteria excluded systemic conditions contraindicating surgery and generalized bony disorders.

The patients were treated with placement of a custom made zirconia porous scaffold along with buccal advancement flap.

\section{Materials}

\section{Zirconia Porous Scaffold (Tosoh Co., Yamaguchi, Japan) (Fig. 1a)}

It is a custom made highly porous scaffold with $4 \mathrm{~mm}$ thickness. It was used to cover the oroantral defect to offer protection to the soft tissue flap and help in cell adhesion, proliferation and differentiation promoting bone regeneration. It is introduced into the defect after being sterilized by gamma rays. 


\section{- Bone Model (Fig. 1b)}

This is a model representing the bone of the jaw with the defect, made out of a photopolymer resin (Edentstone) which is a photosensitive material in liquid form that solidifies under UV lights. A virtual surface for the model was reconstructed from the CBCT by OnDemand3DTM (OnDemand3D Technology Inc. U.S.A) to be printed by stereolithography 3D printing method.

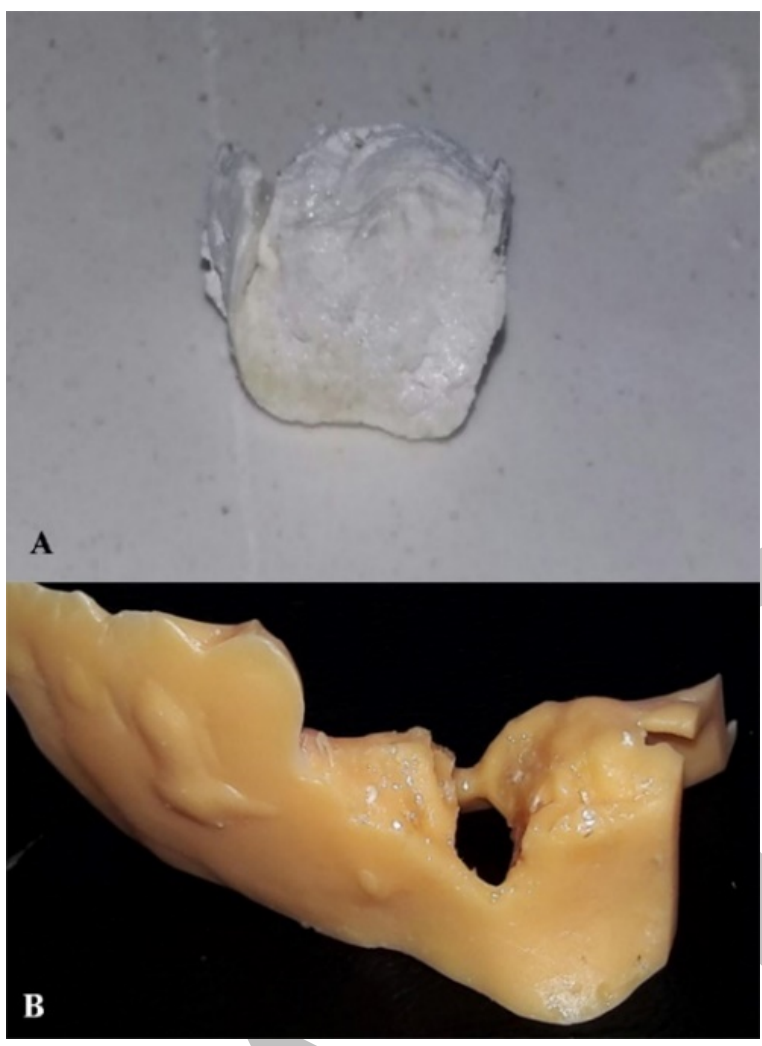

Figure (1): Zirconia porous scaffold

\section{Steps to obtain the required scaffold}

- An impression for the bone model with the defect was taken by addition silicon.

- Pouring of the impression by investment and wait till it hardens.

- Sintering for the investment was done at $1250^{\circ} \mathrm{C}$ for 8 hrs.

- Preparation of the scaffold as follows:

\section{Solvent casting and salt leaching techniques}

- Zirconia powder was mixed with surface adhesive and water soluble salt (sodium chloride) particles. The scaffold pressed on the investment and shaped to the required form. (Fig. 2a)

- After setting, the scaffold was removed and sintered at $1250^{\circ} \mathrm{C}$ for 6 hrs. After sintering, the scaffold was placed in water for leaching out of the salt particles by evaporation and we obtain a porous scaffold with accurate shape and size.

- The scaffold fitted into the defect of the bone model before sterilization to make sure for its accuracy as in the patient's mouth. (Fig. 2b)

- Scanning electron microscope (SEM) was done to measure the average pore size, and the percentage of the porosity.

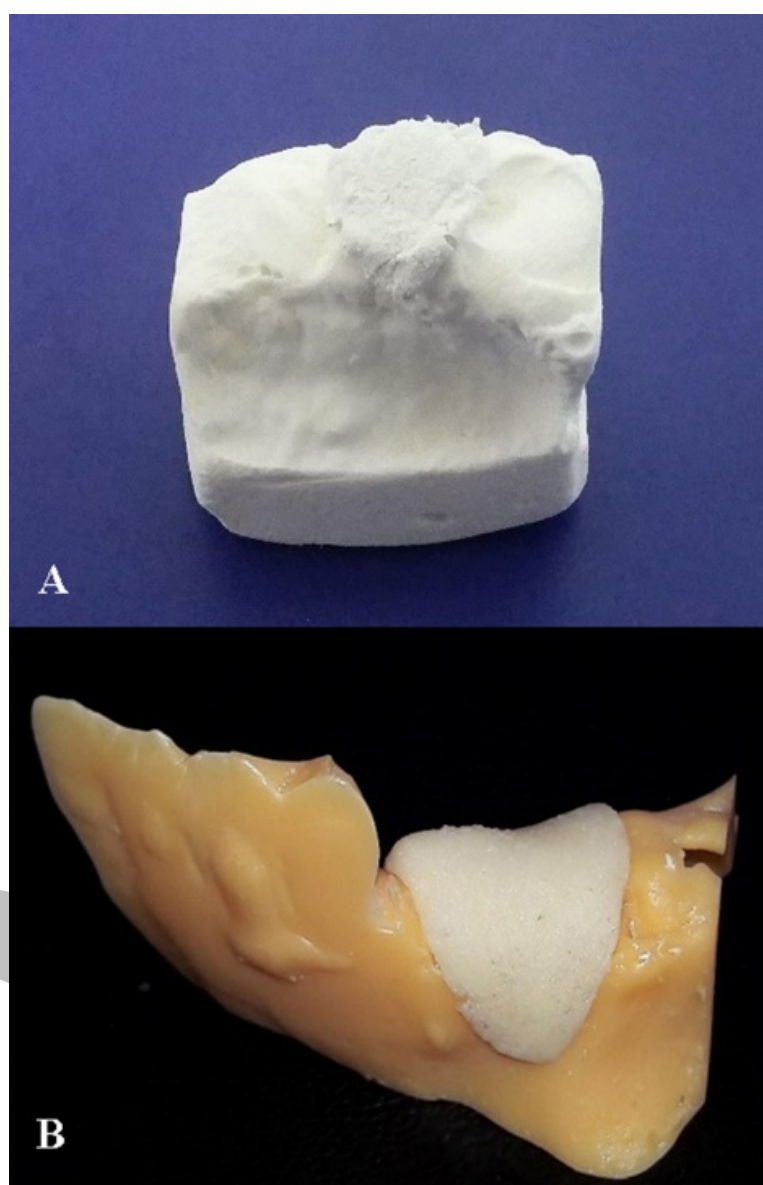

Figure (2):A: Scaffold on the investment, B: Scaffold on the model.

\section{METHODS}

I- Preoperative assessment and examination

All patients were assessed and evaluated by proper history taking, clinical and radiographical examination as follows:

\section{A- History of the patient}

A detailed case history was recorded for each patient including personal data of the patient, date and time of incidence of the communication, time of last dental extraction, history and cause of tooth extraction, nature of extraction, and history of any edema or swelling in the area.

\section{B- Clinical examination}

Both extraoral and intraoral examination were done through inspection and palpation. Extraoral examination included detection of swelling with presence or absence of facial deformity, nasal discharge from nostril of the ipsilateral side, tenderness over the cheek area and palpation of lymph nodes. Intraoral examination included size and site of the OAF, presence or absence of polyps, presence of purulent discharge from the fistula, postnasal discharge, presence of swelling buccal or palatal, condition of neighbouring teeth, previous surgical intervention. Valsalva maneuver (4) was done to confirm the communication. This was done by asking the patient to close both his mouth and nose and attempt to blow, and then immediately opening his mouth to see if any air bubbles appear in the site of presumed defect.

\section{C- Radiographical examination}

A cone-beam computed tomography (CBCT) was done for every patient to assess size of bone defect and any foreign body in the sinus. The preoperative bone density was measured from the CBCT to be compared with the amount of bone formed at the end of the 3 months period. Bone 
density assessment was done using Ondemand software (OnDemand, Cybermed, Korea) where ten points were taken at the region of interest.

\section{II- Pre-operative preparation}

Each patient was prepared by irrigation of the sinus by saline until disappearance of signs of infection. Oral hygiene care and blood analysis and any other required investigations were undertaken to be fit for the surgery. Informed consent was signed by the patient prior to the operation.

\section{III- Operative Phase}

The operations were done under general anaesthesia, using intravenous induction with propofol and then maintained with inhalational isoflurane

The operation steps included decoring of the OAF with a Bard Parker blade number 11. (Fig. 3a), then a buccal advancement mucoperiosteal flap was done using scalpel blade No.15 by doing two vertical divergent incisions through the buccal mucoperisteum and extended superiorly on each side of the OAF to be reflected. (Fig. 3b), zirconia porous scaffold then placed into the defect. (Fig. 3c) Afterwards a horizontal releasing incision was done on the periosteal side of the flap and finally coverage of the defect and the scaffold with the buccal advancement flap and suturing it using water tight mattress interrupted sutures. (Fig. 3d)

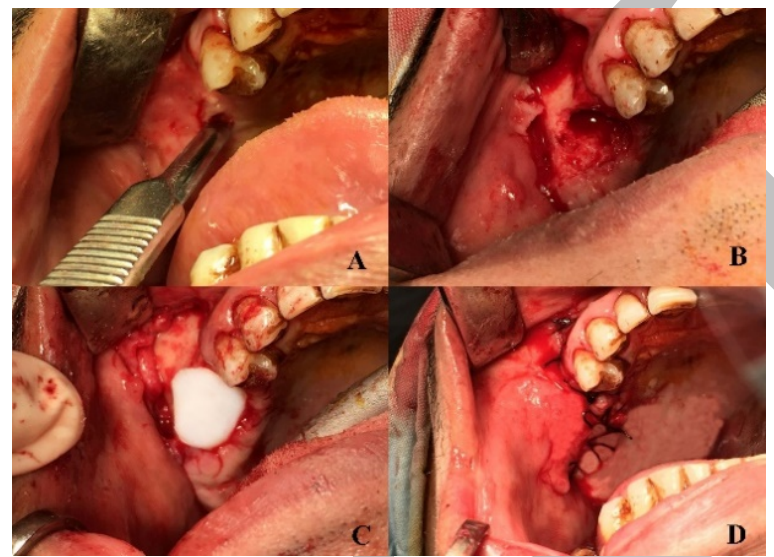

Figure (3):A: Decoring of the fistulous tract. B: Buccal flap reflection, C: Zirconia scaffold placement, D: Suturing of the flap.

\section{IV- Postoperative phase and instructions}

The patients were asked to apply cold fomentations for 24 hours, and to avoid any mouthwash, hot food or drinks, negative or positive pressure on the wound for 24 hours. Sutures were removed after 2 weeks to prevent food accumulation and chance of infection.

\section{Postoperative medication was prescribed as follows}

- Chlorhexidine mouthwash after 24 hours to maintain their oral hygiene.

- Broad spectrum amoxicillin and clavulanic acid as antibiotic (Augmentin, GlaxoSmithKline, Hungary) (1 gram, twice a day).

- Metronidazole (Flagyl, Pfizer, United States of America) for anaerobic bacteria (500mg, three times a day).

- Anti-edematous chymotrypsin and trypsin to control any edema (Alphintern, Amoun Pharmaceuticals, Egypt) (one to two tablets three times a day).

- Diclofenac sodium for analgesia and anti-inflammatory (Cataflam, Novartis, Egypt) (50mg, twice a day).
- Nasal decongestant, oxymetazoline hydrochloride 0.05\% (Afrin, Bayer Group Wuppertal-Barmen, Germany) (one drop in each nostril three times a day) to relieve nasal obstruction and encourage drainage.

\section{V- Follow up evaluation}

\section{a. Clinical evaluation}

Clinical evaluation was done at 2 weeks, 1 month and 3 months postoperatively to observe postoperative pain (visual analogue scale (10), presence of any bleeding and/or infection, and the healing of the mucoperiosteal flap (This was done according to a score from 1 to 4 , one being completely healed and 4 having significant dehiscence) (11).

\section{b. Radiographic examination}

Panoramic x-ray was carried out 2 weeks postoperative to make sure that the scaffold was in its place. CBCT was also carried out 3 months postoperative to evaluate amount of bone formation in the oroantral defect. The bone density was measured at that time, and was used to calculate the percentage change from the preoperative bone density. Ten points were taken at the region of interest.

\section{VI- Statistical analysis of the data (12)}

After data were collected it was revised, coded and fed to statistical software IBM SPSS version 20.0. (13). The given graphs were constructed using Microsoft excel software. All statistical analysis were done using two tailed tests and alpha error of 0.05 . $\mathrm{P}$ value less than or equal to 0.05 was considered to be statistically significant.

The following statistical tests were used:

\section{A. Descriptive statistics:}

included the mean with standard deviation for the numeric data while percent to describe the frequency of each category for categorical data. Regarding skewed data (with outliers), median with range were used.

\section{B. Analysis of numeric data}

1. One-Sample Kolmogorov-Smirnov Test: a procedure compares the observed cumulative distribution function for a variable with a specified theoretical distribution which was the normal distribution at the current data (testing for distributional assumption for numerical data) then the following statistical analysis was done:

a. Repeated Way ANOVA: it is a parametric statistical test that used to compare the means for quantitative data (Pain) of over time for variable which follow a normal distribution. b. Wilcoxon test: a non- parametric statistical test used to compare median bone density before and after intervention as bone density was skewed variable.

\section{Analysis of categorical data}

a. Cochrane Q test: It is a statistical method used to test for significance of differences at frequencies of dichotomous variable (infected/Not infected) over time period

b. Friedman Test: A statistical method used to test for significance at frequencies of wound healing score at different study phases.

\section{RESULTS}

The study was performed on ten patients; five males and five females. They were treated in the Oral and Maxillofacial Surgery Department, Faculty of Dentistry, Alexandria University. Patients' age ranged from 22 to 52 years old (with a mean value of $35.1 \pm 10.0$ ).

\section{Preoperative Findings}

The patients gave a history of the duration of the oroantral communication ranging from 3 weeks to 50 months. The cause of the oroantral fistula was mainly due to extraction 
of the maxillary first molar, with only one case due to extraction of maxillary second premolar, and one due to maxillary second molar. The size of the OAFs ranged from 6 to $9 \mathrm{~mm}$ width.

\section{Surface analysis of zirconia scaffold}

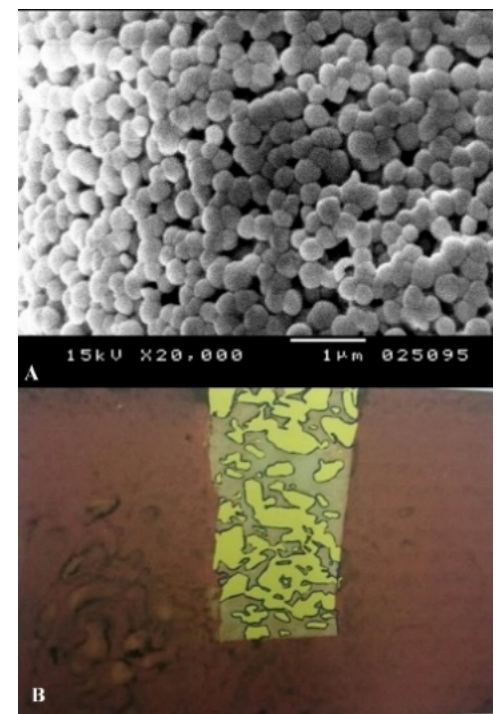

Figure (4): A: Porous zirconia scaffold with perfect interconnected pore structure, B: Calculations of the porosity in zirconia scaffold $=79 \%$ of total volume.

Scanning electron microscope (SEM) was used to measure the average pore size (Fig. 4a), and the percentage of the porosity (Fig. $4 \mathrm{~b})$. Pore size and porosity percentage was found to be $100 \mu \mathrm{m}$ and $79 \%$ respectively.

\section{Clinical Results}

Clinical evaluation was done at 2 weeks, 1 month and 3 months postoperatively to observe postoperative pain, infection, healing and stability of the scaffold by clinical palpation.

In relation to pain, there was a significant decrease of pain as the postoperative period increases, with the maximum pain intensity immediately postoperative. There was no significant postoperative bleeding nor edema in all cases. (Fig. 5)

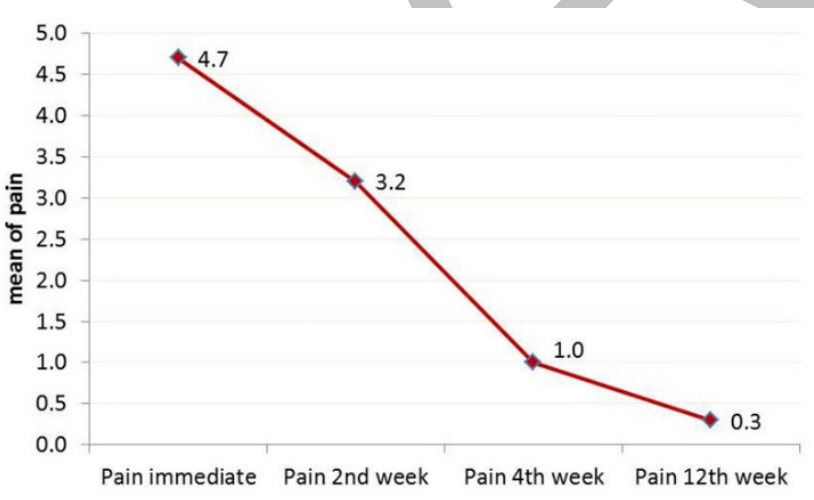

Figure (5):Comparison between the different follow-up periods according to pain.

Postoperative infection was recorded in $20 \%$ of the patients after two weeks of the operation with none of the patients having infection either four weeks or twelve weeks postoperatively.

According to the healing of the soft tissue flap, closure of the wound was recorded in the second week postoperative, along with the fourth and twelfth week. This was done according to a score from 1 to 4, one being completely healed and 4 having significant dehiscence. A significant improvement in wound healing was observed across the follow-up period. (Fig. 6)

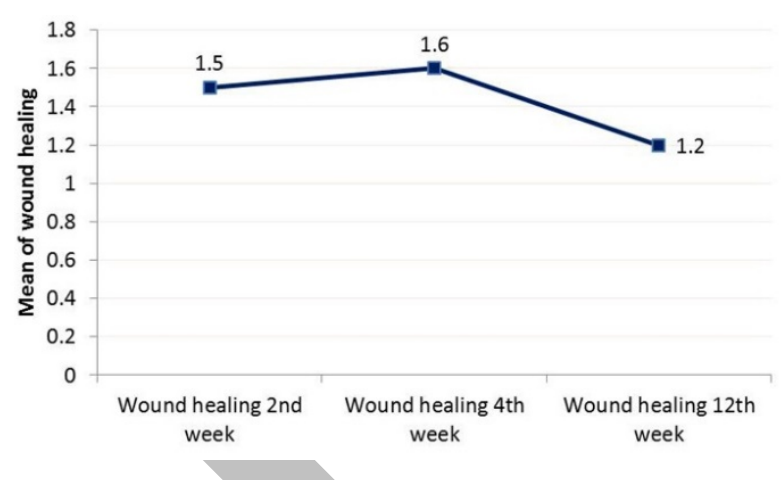

Figure (6): Comparison between the different follow-up periods according to healing of wound.

In the studied cases, only two patients reported graft rejection and lost the scaffold in full prior to the end of the follow-up period. The wound actually didn't heal in those patients due to infected wound margins and they required further treatment later on.

\section{Radiographic Results}

Bone density were measured (Hounsfield unit) preoperatively for each patient and these measurements were considered as a baseline. There was an increase in the amount of bone formation at all levels of measurements, where the mean of bone density was 407.0 preoperatively, and 596.7 postoperatively.

There was a significant increase in bone density from the baseline by 41.2 percentage change. (Table 1 )

Table (1): Comparison between the studied cases according to change of bone density.

$\mathrm{Z}$ : Z for Wilcoxon test.

$*$ : Statistically significant at $\mathrm{P} \leq 0.05$.

\begin{tabular}{|l|l|l|l|l|l|}
\hline $\mathbf{z}$ & Range & $\begin{array}{l}\text { Mean } \\
\pm \text { SD }\end{array}$ & Median & $\begin{array}{l}\text { Mean } \\
\text { change } \%\end{array}$ & $\mathbf{Z}(\mathbf{P})$ \\
\hline Pre & $\begin{array}{l}241.0 \\
-\end{array}$ & $\begin{array}{l}407.0 \\
\pm 112.7\end{array}$ & 419.6 & & \\
& 664.1 & & $41.2 \%$ & $\begin{array}{l}2.8 \\
(0.005) *\end{array}$ \\
\hline Post & $\begin{array}{l}495.3 \\
-\end{array}$ & $\begin{array}{l}596.7 \\
\pm 79.6\end{array}$ & 591.3 & & \\
\hline
\end{tabular}

\section{DISCUSSION}

The major cause of odontogenic maxillary sinusitis is iatrogenic, one of which is the oroantral communications, accounting for $47.5 \%$ of iatrogenic causes (1). Oro-antral fistulas that are formed due to epithelialization of a long standing communication must be surgically treated. It has low chance of spontaneous healing and must be closed to prevent infection and inflammation of the maxillary sinus $(5,14,15)$. A key component in tissue engineering for bone regeneration is the use of scaffold that serve as a template for cell interactions and the formation of boneextracellular matrix to provide structural support to the 
newly formed tissue (16). Scaffolds must posses a highly porous structure with an open fully interconnected geometry to provide a large surface area that will allow cell ingrowth, uniform cell distribution, and facilitate the neovascularization of the contruct (17).

This study was undertaken to fabricate a zirconia scaffold with a porous surface that improves mechanical interlocking between the surrounding natural bone, providing greater mechanical stability at this critical interface (18), where pores are necessary for bone tissue formation because they allow migration and proliferation of osteoblasts and mesenchymal cells, as well as vascularization (19).

In this study, the gender distribution was equally distributed between males and females. This was in accordance to a study by Yabroudi and Dannan in 2008 (20), Del Rey-Santamaria et al. in 2006 (4) and Freudlsperger et al. in 2014 (21). Other authors as FrancoCarro et al. in 2011 (3) and Amaratunga in 1986 (22) have found that oroantral fistulas occur more in male patients, which may be due to the more difficult extraction in males.

The age distribution observed was between the third decade and sixth decade of life. Yabroudi and Dannan in 2008 (20) also experienced a similar average of 40 years old in his research. Franco-Carro et al. (3) stated that there is no total agreement of the common age group that oroantral fistulas occur in. Del Rey-Santamaria et al. in 2006 (4) showed that it is more common in the third decade, Amaratunga in 1986 (22) in the fourth decade, and Punwutukorn et al. in 1994 (23) in the sixth decade.

Oroantral fistula (OAF) most commonly occurs as a complication of maxillary molar or premolar extraction. The primary reason is the anatomic proximity of the root apices to the sinus floor or projection of the roots within the maxillary sinus (24). Punwutukorn et al. in 1994 (23) showed that extraction of the upper first molars is the most common etiologic factor for oroantral communications. In our patients, we found that all of the cases were due to the extraction of teeth, with the $1^{\text {st }}$ molar tooth is the commonest one (80\% of the cases) involved with the development of the fistula formation.

Postoperative infection was recorded with $20 \%$ of the cases showing up with infected wounds at the two weeks postoperative with none of the patients having infection either four weeks or twelve weeks postoperative. This could be accredited as one of the reasons for a slower rate of healing in these patients.

The surgical method used in this study was the buccal trapezoidal flap because of its simplicity, wide range of indications, and being the most commonly used by clinicians (25).

It was observed that there was a significant improvement in wound healing in $80 \%$ of the cases with only two of the patients experienced infected wound margins with wound dehiscence and high wound healing scores. These findings were clinically significant at the second postoperative week.

Wound dehiscence occurring in those patients was due to coughing and sneezing after surgery with misunderstanding from the patients. This might create tension on the buccal flap leading to improper healing. This agrees with the results by Skoglund et al. in 1983 (26) where excessive tension on flap margins was mentioned to be one of the most important reasons for failure of treatment of oroantral fistulas.

Results observed in the healing of the studied cases was similar to those found by Guven in 1998 (27), in which none of the cases experienced complications and were properly healed. Hernando et al. in 2010 (14) also stated that those cases that recurred postoperatively actually spontaneously closed within one and four months after. This was comparable to what happened in this study, where healing to wound dehiscence also occurred without further intervention.

An important remark is that two out of ten patients reported graft rejection and the actual loss of the scaffold as it is. They mentioned that they felt something in the oral cavity under the flap and eventually it fell out. Hariram et al. in 2010 (15) also had a similar experience of graft rejection who used hydroxyapatite crystals embedded within collagen sheath in closure of oroantral defects. Those patients' wound were not healed at the end of the follow-up period of 12 weeks.

In relation to pain, pain intensity decreased as the postoperative period increases, with the maximum pain intensity was immediately postoperative.

Roy et al. in 2003 (28) reported improved tissue ingrowth and new bone formation on the composite scaffolds (polylactide containing $20 \%$ wt. $\beta$ - tri-calcium phosphate) by increasing the porosity from $80 \%$ to $88 \%$. Moreover, Kujala et al. in 2003 (29) investigated the bone formation of $\mathrm{Ni}$-Ti metallic scaffolds with two different porosities (66\% and $47 \%$ ) in a rat femoral defect. Although no statistically difference was observed, the metallic scaffold with higher porosity had higher boneimplant contact.

There was no significant effect on the bone formation level in the poly (propylene fumarate) scaffolds with different pore sizes (300-500 and 600-800) when implanted subcutaneously or in cranial defect of rabbit (30).

Among many fabrication methods, the solvent-casting and particulate leaching technique was adopted in this study, where the zirconia powder were mixed with water solouble salt (sodium chloride) particles then the mix pressed on the investment and shaped to the required form, then the salt particles were leached out by evaporation to obtain a highly porous structure (79\% porosity).

Zirconia was the material of choice used in this study as it performs better osseointegration in comparison to other materials because it does not interfere with the growth of osteoblasts (31).

The geometrical factors of a scaffold, such as the pore size, porosity and the pore interconnectivity, are also of crucial importance, because these affects the diffusion of the nutrients, cell attachment, migration, and tissue ingrowth that are necessary for the bone formation process (32).

In this study, the porous structure obtained with a large pore size $(100 \mu \mathrm{m})$ and high porous structure $(79 \%$ porosity) are expected to be sufficient to permit tissue ingrowth and anchor the scaffold to the surrounding bone as well as to supply blood and nutrients to bone like vascular canals.

This was in accordance to the studies by Hulbert et al. in 1970 (33) who stated that the minimum pore size 
required to regenerate mineralized bone is generally considered to be ( $\sim 100 \mathrm{um})$, where calcium aluminate cylindrical pellets with $46 \%$ porosity were implanted in dog femoral.

The sintering process is the most common method for fabricating porous scaffolds as stated by SchultzeMosgau et al. in 2000 (34).

For the growth of osteoblasts, porous surfaces is critical, because cells are attached to the pore and can spread through interconnected pore. Therefore, the activity of osteoblast is better on porous surfaces than on simple rough surface. The optimal pore size for osteoblast activity is $100 \mu \mathrm{m}-400 \mu \mathrm{m}$ as stated by Itälä et al. in 2001 (35). In this study, the SEM microghraphs showed that the pore size of the zirconia scaffold was $100 \mu \mathrm{m}$, which is a suitable environment for osteoblastic activity and formation of a new bone in the defective site.

The scaffold with a higher porosity is suggested to be more favorable in terms of bone formation ability, the mechanical benefits resulting from the reduction in porosity should not be ignored, since the mechanical functioning of a scaffold is of special importance in the process of bone formation in the oroantral defect. From this point of view, the selection of a scaffold should be made by finding a compromise between the mechanical properties and bone formation ability.

\section{CONCLUSIONS}

Based on the results of this study, it is concluded that the clear interconnected porous surface and the high porosity of zirconia porous scaffold are the keys to enhance new bone formation in oroantral defects.

\section{CONFLICT OF INTEREST}

The authors declare that they have no conflicts of interest.

\section{REFERENCES}

1. Simuntis R, Kubilius R, Vaitkus S. Odontogenic maxillary sinusitis: A review. Stomatologija. 2014;16:39-43.

2. Malik NA. Textbook of oral and maxillofacial surgery. 2nd ed. New Delhi: Jaypee Brothers Publishers, 2008:563-86.

3. Franco-Carro B, Barona-Dorado C, MartinezGonzalez MJ, Rubio-Alonso LJ, Martinez-Gonzalez JM. Meta-analytic study on the frequency and treatment of oral antral communications. Med Oral Patol Oral Cir Bucal. 2011;16:682-7.

4. Del Rey-Santamaria M, Valmaseda Castellon E, Berini Aytes L, Gay-Escoda C. Incidence of oral sinus communications in 389 upper third molar extraction. Med Oral Patol Oral Cir Bucal. 2006;11:334-8.

5. Borgnovo A, Berardinelli FV, Favale M, Maiorana C. Surgical Options In Oroantral Fistula Treatment. Open Dent J. 2012;6:94-98.

6. Candamourty R, Jain MK, Sankar K, Babu MR. Double-layered closure of oroantral fistula using buccal fat pad and buccal advancement flap. J Nat Sc Biol Med. 2012;3:203-205.
7. Scattarella A, Ballini A, Grassi FR, Carbonara A, Ciccolella F, Dituri A, et al. Treatment of oroantral fistula with autologous bone graft and application of a non-resorbable membrane. Int J Med Sci. 2010;7:267271.

8. Langer R, Vacanti JP. Tissue engineering. Science. 1993;260:920-6.

9. Langer R, Tirrell DA. Designing materials for biology and medicine. Nature. 2004;428:487-92.

10. Hawker GA, Mian S, Kenzerska T, French M. Measures of adult pain: Visual analog scale for pain (vas pain), numeric rating scale for pain (nrs pain), mcgill pain questionnaire (mpq), short-form mcgill pain questionnaire (sf-mpq), chronic pain grade scale (cpgs), short form-36 bodily pain scale (sf-36 bps), and measure of intermittent and constant osteoarthritis pain (ICOAP). Arthritis Care Res (Hoboken). 2011;63:S240-52.

11. Jovanovi'c G, Buri'c N, Tijani'c M. Stimulation of mucoperiosteal slice epithelialization by small power laser after the primary plastic of oroantral communication. Medicinski Pregled. 2010;63:188-93.

12. Bickel PJ, Doksum KA. Mathematical statistics: basic ideas and selected topics. London: CRC Press, Taylor and Francis Group, 2015.

13. Kirkpatrick L, Feeney B. A simple guide to IBM SPSS statistics for version 20.0. Student edition. Belmont, CA: Wadsworth, Cengage Learning, 2013.

14. Hernando J, Gallego L, Junquera L, Villarreal P. Oroantral communications. A retrospective analysis. Med Oral Patol Oral Cir Bucal. 2010;15:e499-503.

15. Hariram U, Mohammad S, Singh R, Singh G, Malkunje LR. Buccal fat pad versus sandwich graft for treatment of oroantral defects: A comparison. Natl J Maxillofac Surg. 2010;1:6-14.

16. Li WJ, Laurencin CT, Caterson EJ, Tuan RS. Electrospun nanofibrous structure: A novel scaffold for tissue engineering. J Biomed Mater. 2002;60:61321.

17. Léon y Léon CA. New perspectives in mercury porosimetry. Advances in colloid and interface Science, 1998

18. Story BJ, Wanger WR, Gaisser DM, Cook SD, RustDawicki AM. In vivo performance of a modified CSTi dental implant coating. Int J Oral Maxillofac Implants. 1998;13:749-57.

19. Kuboki Y, Takita H, Kobayashi D, Tsuruga E, Murata M. BMP-induced osteogenesis on the surface of hydroxyapatite with geometrically feasible and non feasible structures: Topology of osteogenesis. J Biomed Mater Res. 1998;39:190-9.

20. Yabroudi F, Dannan A. A Comparison between Submucosal Connective Tissue Palatal Flap and Conventional Pedicle Palatal Flap for the Closure of Oroantral Fistulae. Intern J Dent Sci. 2008;8(1).

21. Freudlsperger C, Castrillon-Oberndorfer G, Baechli H, Hoffmann J, Mertens C, Engel M. The value of 
ultrasound-assisted pinned resorbable osteosynthesis for cranial vault remodeling in craniosynostosis. J Craniomaxillofac Surg. 2014;42:503-7.

22. Amaratunga NA. Oroantral fistulae-a study of clinical, radiological and treatment aspects. Br J Oral Maxillofac Surg. 1986;24:433-7.

23. Punwutikorn J, Waikakul A, Pairuchvej V. Clinically significant oroantral communications-a study of incidence and site. Int J Oral maxillofac Surg. 1994;23:19-21.

24. Lazow SK. Surgical management of the oroantral flap procedures. Oper Tech Otolaryngol Head Neck Surg. 1999;10:148-52.

25. Abuabara A, Cortez AL, Passeri LA, De Moraes M, Moreira RF. Evaluation of different treatments for oroantral/ oronasal communications: experience of 112 cases. Int J Oral Maxillofacial Surg. 2006;35:155-8.

26. Skoglund LA, Pedersen SS, Holst E. Surgical management of 85 perforations to the maxillary sinus. Int J Oral Surg. 1983;12:1-5.

27. Guven O. A clinical study on oroantral fistulae. J Cranio Maxillofac Surg. 1998;26:267-71.

28. Roy TD, Siomon JL, Ricci JL, Rekow ED, Parson JR. Performance of degradable composite bone repair products made via three-dimensional fabrication ztechniques. J Biomed Mater. 2003;66:283-91.

29. Kujala S, Ryhanen J, Danilov A, Tuukkanen J. Effect of porosity on the oseointegration and bone ingrowth of a weight bearing nickel-titanium bone graft substitute. J Biomater. 2003;24:4691-7.

30. Fisher JP, Vehof JW, Dean D, Van der Waerden JP, Holland TA, Mikos AG, et al. Soft and hard tissue response to photocrosslinked poly (propylene fumarate) scaffolds in a rabbit model. J Biomed Mater. 2002;59:547-56.

31. Piconi C, Maccauro G. Zirconia as a ceramic biomaterial. Biomaterials. 1999;20:1-25.

32. Karageorgiou V, Kaplan D. Porosity of 3D Biomaterial scaffolds and osteogenesis. J Biomater. 2005;26:5474-91.

33. Hulbert SF, Young FA, Mathewes RS, Klawetter JJ, Talbert CD, Stelling FH. Potential of ceramic materials as permanently implantable skeletal prosthesis. J Biomed Mater Res. 1970;4:433-56.

34. Schultze-Mosgau S, Schliephake H, RadespielTröger M, Neukam FW. Osseointegration of endodontic endosseous cones: zirconium oxide vs titanium. Oral Surg Oral Med Oral Pathol Oral Radiol Endod. 2000;89:91-8.

35. Itälä AI, Ylänen HO, Ekholm C, Karlsson KH, Aro HT. Pore diameter of more than 100 micron is not requisite for bone ingrowth in rabbits. $\mathrm{J}$ Biomed Mater Res. 2001;58:679-8 